\title{
Tropical land use drives endemic versus exotic ant communities in a global biodiversity hotspot
}

\author{
Anjaharinony A. N. A. Rakotomalala ${ }^{1,2}$ (D) Annemarie Wurz ${ }^{2}$. \\ Ingo Grass ${ }^{3}$ (D) . Dominic A. Martin ${ }^{4,5}$ (D) Kristina Osen ${ }^{6}$ (D) . \\ Dominik Schwab ${ }^{2}$ D $\cdot$ Marie Rolande Soazafy ${ }^{6,7,8}$ (D) Teja Tscharntke ${ }^{2,9}$. \\ Lala H. Raveloson Ravaomanarivo ${ }^{1}$
}

Received: 19 March 2021 / Revised: 5 October 2021 / Accepted: 14 October 2021 /

Published online: 21 October 2021

(c) The Author(s) 2021

\begin{abstract}
Understanding how land-use change affects biodiversity is a fundamental step to develop effective conservation strategies in human-modified tropical landscapes. Here, we analyzed how land-use change through tropical small-scale agriculture affects endemic, exotic, and non-endemic native ant communities, focusing on vanilla landscapes in north-eastern Madagascar, a global biodiversity hotspot. First, we compared ant species richness and species composition across seven land-use types: old-growth forest, forest fragment, forest-derived vanilla agroforest, fallow-derived vanilla agroforest, woody fallow, herbaceous fallow, and rice paddy. Second, we assessed how environmental factors drive ant species richness in the agricultural matrix to identify management options that promote endemic and nonendemic native while controlling exotic ant species. We found that old-growth forest, forest fragment, and forest-derived vanilla agroforest supported the highest endemic ant species richness. Exotic ant species richness, by contrast, was lowest in old-growth forest but highest in herbaceous fallows, woody fallows, and rice paddy. Rice paddy had the lowest non-endemic native ant species richness. Ant species composition differed among land-use types, highlighting the uniqueness of old-growth forest in harboring endemic ant species which are more sensitive to disturbance. In the agricultural matrix, higher canopy closure and landscape forest cover were associated with an increase of endemic ant species richness but a decrease of exotic ant species richness. We conclude that preserving remnant forest fragments and promoting vanilla agroforests with a greater canopy closure in the agricultural matrix are important management strategies to complement the role of oldgrowth forests for endemic ant conservation in north-eastern Madagascar.
\end{abstract}

Keywords Ant $\cdot$ Conservation $\cdot$ Land-use change $\cdot$ Madagascar $\cdot$ Slash-and-burn agriculture $\cdot$ Vanilla agroforest

Communicated by Akihiro Nakamura.

Anjaharinony A. N. A. Rakotomalala andrynyaina001@gmail.com

Extended author information available on the last page of the article 


\section{Introduction}

Tropical forests harbor the highest proportion of biodiversity worldwide (Myers et al. 2000). However, they are decimated and fragmented due to human land use, often resulting in a mosaic landscape consisting of forest patches and various agricultural land-use systems (Grass et al. 2020). Although forest conversion and degradation constitute the major drivers of tropical biodiversity decline (Gibson et al. 2011), many species remain in the agricultural landscape (Belshaw and Bolton 1993). Assessing the implications of land-use change for biodiversity is, therefore, a fundamental step to develop effective conservation strategies for tropical agricultural landscapes and to identify sustainable land-use options that prevent further biodiversity loss.

Ants are among the most abundant insect groups in terrestrial ecosystems (Passera and Aron 2005). Their diversity and endemism rate peak in tropical regions (Lach et al. 2010). Ants are involved in diverse ecosystem functions such as soil turnover (Folgarait 1998), seed dispersal (Retana et al. 2004), predation (Cerdá and Dejean 2011), and food provision for other animal groups like birds (Dean and Milton 2018). However, ants, in particular native ants, are sensitive to human land use, such as logging and forest conversion, which often reduces species richness and changes the species composition of ant communities (Dunn 2004; Delabie et al. 2007; Ottonetti et al. 2010). On the contrary, habitat disturbance generally promotes invasion of exotic ant species, which can be problematic for the native ant community, because of their competitive behavior on resources (Holway et al. 2002). In addition, the structure of ant community may also be driven by environmental factors such as canopy openness, vegetation structure, deadwood volume, and landscape forest cover (Luke et al. 2014; Solar et al. 2016). Analyzing how these factors influence species richness can thus help identify land-use management options that result in few exotic species to efficiently preserve the native (endemic) ant community.

Madagascar, a global biodiversity hotspot, hosts more than 1200 ant species, with $93 \%$ of described species are endemic to the island, and 41 species are exotic (Myers et al. 2000; Fisher and Christian 2019). Forests are indispensable for the majority of Madagascar's endemic biodiversity (Irwin et al. 2010). However, deforestation through agricultural practices has led to a loss of 44\% of Madagascar's forest cover between 1953 and 2014 (Clark 2012; Vieilledent et al. 2018). Today, protected areas constitute the main conservation strategy to protect Madagascar's remaining biodiversity (Gardner et al. 2018). However, little is known about conservation opportunities in the agricultural landscape outside protected areas. Exotic ants could be problematic for Madagascar's native ant community, as demonstrated in a previous study that found aggressive competition of exotic ant species towards native ant species (Dejean et al. 2010). Thus, conservation strategies need to include the management of exotic species to protect native ant species.

North-eastern Madagascar holds proportionally more forest than other regions of the island. Nonetheless, these are also subject to transformation, mainly through slashand-burn agriculture for hill rice cultivation by smallholders (Zaehringer et al. 2015). Slash-and-burn agriculture consists of cutting down the forest or woody fallow land, burning the plant biomass, and cultivating rice. This is followed by a fallow period, after which an additional cycle of slash-and-burn cultivation can commence. Northeastern Madagascar also supplies the biggest share of vanilla to the global market (FAO 2020). The increase of global demand and the rise of vanilla prices between 2012 and 2019 has triggered an expansion of vanilla cultivation in the region, where forest or fallow land is transformed into vanilla agroforests (Llopis et al. 2019). Here, 
the biodiversity value of vanilla agroforests may depend on land-use history, meaning whether the vanilla agroforest was established at the expense of forest (forest-derived), driving forest transformation, or whether it was planted on formerly fallow land (fallow-derived), rehabilitating formerly burned land (Martin et al. 2020a). However, this important distinction is hardly made in land-use research (Martin et al. 2020a), but research on plants (Osen et al. 2021; Raveloaritiana et al. 2021) and birds (Martin et al. 2021 ) indicates differences in species richness and composition depending on land-use history, particularly for endemics.

Overall, the landscape of north-eastern Madagascar is characterized by a mosaic of forest fragments, rice cultivation (irrigated and rainfed), vanilla agroforests, and fallow lands (Zaehringer et al. 2015). Vanilla agroforests are characterized by a combination of shade trees and Vanilla planifolia plants, leading to a structurally diverse habitat with medium to high canopy closure (Osen et al. 2021). Woody and herbaceous fallows and rice paddy have significantly lower or no canopy closure and structurally and taxonomically simplified vegetation (Osen et al. 2021). Recent studies assessed the impact of land-use change on biodiversity in north-eastern Madagascar, highlighting the value of vanilla agroforests to complement forests for the conservation of vertebrates including birds and lemurs, plants, and ecosystem functions (Hending et al. 2018, 2020; Osen et al. 2021; Schwab et al. 2021; Raveloaritiana et al. 2021). Invertebrates, in particular ants, have only been studied in forest habitats rather than in the agricultural landscape.

In this paper, we report how land-use change through smallholder agriculture affects endemic, exotic, and non-endemic native ant communities in north-eastern Madagascar. First, we compared ant species richness and species composition across seven land-use types: old-growth forest, forest fragment, forest-derived vanilla agroforest, fallow-derived vanilla agroforest, woody fallow, herbaceous fallow, and rice paddy. Second, we assessed how environmental factors drive ant species richness in the agricultural matrix to identify management options that promote endemic and nonendemic native ant species while controlling exotic ant species.

\section{Materials and methods}

\section{Study region and sampling design}

We carried out our study in the central part of the SAVA region, in north-eastern Madagascar. The climate is warm and humid (UPDR 2003), with $2223 \mathrm{~mm}$ annual precipitation and $24.0{ }^{\circ} \mathrm{C}$ average temperature (average across 80 plots, data retrieved from CHELSA climatologies; Karger et al. 2017). The climax vegetation type is tropical rainforest (Baena et al. 2007).

We studied seven land-use types: old-growth forest (10 replicates), forest fragment (10), forest-derived vanilla agroforest (10), fallow-derived vanilla agroforest (20), woody fallow (10), herbaceous fallow (10), and rice paddy (10). The description of each land-use type is found in Table 1. Overall, we had 80 plots distributed in ten villages and two old-growth forest sites in Marojejy National Park (Fig. 1). The minimum distance to neighboring plots was $719 \mathrm{~m} \pm 438 \mathrm{~m}$. The average plot elevation above sea level was $192 \mathrm{~m} \pm 207 \mathrm{~m}$. We standardized our plot size to a $25 \mathrm{~m}$ radius circle. 
Table 1 Description of land-use types studied in north-eastern Madagascar

\begin{tabular}{ll}
\hline Land-use type & Description \\
\hline Old-growth forest & $\begin{array}{c}\text { Never been burned. Largely untouched by human activity. Located in } \\
\text { Marojejy National Park }\end{array}$ \\
Forest fragment & $\begin{array}{c}\text { Never been burned. Fragmented forest embedded in the agricultural } \\
\text { matrix. Owned by farmers or local community. Used to extract fire- } \\
\text { wood and wood for construction }\end{array}$ \\
Forest-derived vanilla agroforest & $\begin{array}{c}\text { Never been burned. Retained some trees from the original forest which } \\
\text { serve as shade and support for the vanilla plants }\end{array}$ \\
Fallow-derived vanilla agroforest & $\begin{array}{c}\text { Derived from previously slashed-and-burned land used for hill rice cul- } \\
\text { tivation. Burned at least once before being transformed into a vanilla } \\
\text { agroforest. Shade trees are either naturally regenerating or planted }\end{array}$ \\
Previously burned. Vegetation of shrubs and trees regrown subsequently \\
for 4-16 years before data collection \\
Previously burned. Vegetation of herbaceous plants and shrubs re-grown \\
for at least 1 year before data collection \\
Sometimes inundated. Vegetation of herbaceous plants on traversed \\
banks. Chemical pesticides are occasionally used against pests
\end{tabular}

\section{Ant sampling and identification}

We sampled ants using bait and pitfall traps on all plots except the old-growth forest between October and December 2017, and in the old-growth forest between August and December 2018. In each plot, we established five sampling stations: one at the plot center, and four $16 \mathrm{~m}$ away from the plot center in each cardinal direction. At each sampling station, we set bait and pitfall traps $10 \mathrm{~m}$ apart. For bait traps, we put sardine and sugar as bait on two different white flat plastic supports (diameter of $13 \mathrm{~cm}$ ) about $5 \mathrm{~cm}$ apart (illustration in Supplementary Material S1). We set the baits for $30 \mathrm{~min}$ and thereafter collected the specimens present on the white plastic support for $30 \mathrm{~s}$. For pitfall traps, we buried a plastic cup $(9 \mathrm{~cm}$ top diameter, $11 \mathrm{~cm}$ deep, $6 \mathrm{~cm}$ bottom diameter) in the soil with the opening at the same level as the ground surface. We then filled one-third of the plastic cup with $70 \%$ ethanol and few drops of soapy water. We left the pitfall traps active for $48 \mathrm{~h}$. We preserved ant specimens in $70 \%$ ethanol for further identification.

To identify ants to the genera level, we used the identification key from Fisher et al. (2016). We then identified ants to species level using identification keys (e.g. Fisher and Smith 2008; Bolton and Fisher 2014; Rakotonirina and Fisher 2014; Salata and Fisher 2020). If identification was unclear, we identified species as morphospecies. We stored voucher specimens at the Biodiversity Centre in Antananarivo, Madagascar, for reference and further taxonomical study. We assigned our ant species into different origin categories (AntWeb 2020): endemic, exotic, non-endemic native, and unknown ants. In total, we recorded 128 ant species/morphospecies (57 endemic species, 19 exotic species, 18 non-endemic native, and 34 species of unknown origin) distributed in 38 genera and seven subfamilies. In the present study, we excluded the unknown ants but included the results on this category in the supplementary materials (Supplementary Material S2-S4). 


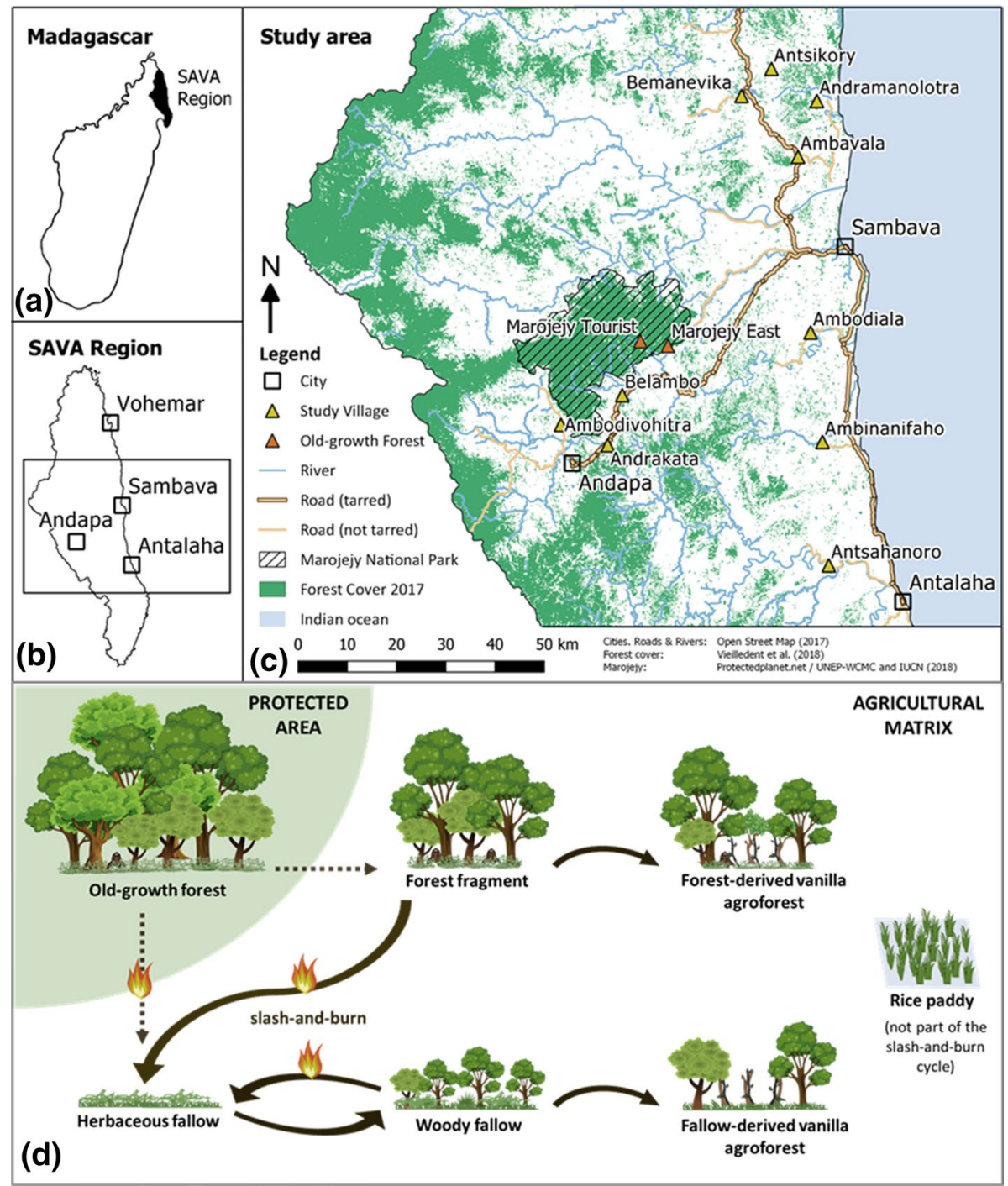

Fig. 1 a Location of the SAVA region within Madagascar, b SAVA region with the four districts Andapa, Antalaha, Sambava, Vohemar and the study area therein, c map of the study area with forest cover and triangles depicting the 10 study villages and 2 old-growth forest sites, and $\mathbf{d}$ our seven land-use types studied summarizing the typical land-use change dynamic through slash-and-burn agriculture for hill rice cultivation in north-eastern Madagascar. Dashed arrows indicate possible, but prohibited transformation of oldgrowth forest. Full arrows represent common transformation trajectories from one land use to another. Rice paddy is not part of the slash-and-burn cycle and represents the most intensive land use in the region

\section{Environmental parameters}

In each plot, we recorded canopy closure, tree species richness, stem density, understory vegetation cover, and lying deadwood volume as local environmental parameters. We counted and identified all trees (woody perennial plants) and tree-like plants (arborescent 
palms and ferns) with a diameter at breast height $\geq 8 \mathrm{~cm}$, from which we extracted data on tree species richness and stem density (number of living stems per ha). To assess canopy closure, we set a Nikon D5100 camera with a fisheye lens and $180^{\circ}$ field of view on a tripod at $2.4 \mathrm{~m}$ height. Then, we took series of hemispherical photographs. We processed the photographs with the "ImageJ" program (Rasband 2014) to create a binary image representing sky and vegetation and applied an automated thresholding technique following the protocol of Beckschäfer (2015). We derived gap fraction values and converted them to canopy closure values, to finally calculate the mean canopy closure percentage per plot (Osen et al. 2021). To estimate the understory vegetation cover of each plot, we adapted the protocol of Van Der Maarel (1966), taking into account the understory such as shrubs, saplings, and non-woody plants. We took photographs with a view from zero to three meters above the ground in each cardinal direction from the plot center. We divided each photograph into six $0.5 \mathrm{~m}$ layers and estimated the understory vegetation cover in $\%$ for each layer. Then, we averaged the understory vegetation cover value from all layers on all photographs to represent a single understory vegetation cover value (in \%) for each plot (Schwab et al. 2021). We measured the diameter and length of all lying deadwood with a midpoint diameter $\geq 10 \mathrm{~cm}$ and length $\geq 100 \mathrm{~cm}$. We excluded deadwood that was already decomposed into powder. We used the equation "deadwood volume $=\left[\left(\pi *\right.\right.$ diameter $\left.\left.^{2}\right) / 4\right]$ * length" to calculate the volume of each lying deadwood piece (Rondeux et al. 2012). We summed up the volume of all lying deadwood pieces per sample area, then upscaled the volume of lying deadwood per hectare. As landscape parameters, we calculated the landscape forest cover percentage within a $250 \mathrm{~m}$ radius buffer surrounding our plots using 2017 landscape forest cover data (Vieilledent et al. 2018).

\section{Data analysis}

We combined data from bait and pitfall traps into a plot/species presence/absence matrix and used the $\mathrm{R}$ version 3.6.3 program for all analysis (R Core Team 2020).

\section{Comparison of ant species richness and composition}

To compare ant species richness between land-use types, we ran generalized linear mixed models (GLMMs) with ant species richness as the response variable, land-use types as the explanatory variable, and Poisson distribution as family, using the glmmTMB function of the glmmTMB package (Brooks et al. 2017). We set village and old-growth forest sites as a random factor to account for potential spatial autocorrelation. We used Tukey's honestly significant difference (Tukey HSD) with Bonferroni correction for pairwise comparison between land-use types.

We performed a permutational multivariate analysis of variance (PERMANOVA, 999 permutations) using the adonis function of the package Vegan (Oksanen et al. 2018) and the pairwise.adonis function with False discovery rate correction of the package pairwiseAdonis (Arbizu 2017) to assess differences in species composition among and between land-use types. Then, we performed a permutational multivariate analysis of dispersion (PERMDISP, 999 permutations) using the betadisp function of the package Vegan to test the homogeneity of dispersion among land-use types (Oksanen et al. 2018). A homogenous dispersion implies that the difference in species composition among land-use types from PERMANOVA is explained by the difference in location of the centroids. We found that heterogeneous dispersion significantly contributes to the differences in endemic 
(PERMDISP, $\mathrm{Df}=6, \mathrm{~F}=5.07, \mathrm{p}=0.002$ ) and exotic (PERMDISP, $\mathrm{Df}=6, \mathrm{~F}=21.65$, $\mathrm{p}=0.001$ ) but not non-endemic (PERMDISP, $\mathrm{Df}=6, \mathrm{~F}=1.45, \mathrm{p}=0.204$ ) ant species composition between our land-use types. We visualized the community structure of each landuse type using non-metric multidimensional scaling (NMDS). We used the dimcheckMDS function of the package goeveg to select any number of dimensions with a good stress value (stress < 0.2) for the NMDS (Goral and Schellenberg 2021). We used Jaccard dissimilarity distance for PERMANOVA, PERMDISP, and NMDS. Additionally, we used the upset function of the package $U p S e t R$ to visualize the number of unique and shared species between land-use types (Gehlenborg 2019).

\section{Environmental parameters as drivers of ant species richness}

Since we aimed to provide applied land management options for ant species conservation in the agricultural matrix, we excluded old-growth forest sites in our models when assessing the environmental parameters driving ant species richness. Additionally, we excluded rice paddy and herbaceous fallow in our model since they do not contain trees, therefore no canopy closure and deadwood, which substantially can affect our model results by driving too much the effect on species richness.

Prior to building our models, we performed a correlation test between all explanatory variables to assess the possible effects of multicollinearity. In case the explanatory variables were strongly correlated (Spearman $|r|>0.7$ (Dormann et al. 2013)), we kept only one of them. We found that canopy closure, stem density, and tree species richness were highly correlated (Supplementary Material S5). We retained canopy closure in our models because stem density and tree richness data were missing in two plots. With GLMMs, we set a full model with ant species richness as the response variable, canopy closure, deadwood, understory vegetation, and forest cover as explanatory variables, and village as a random factor. Since our response variable was count data, we first used the Poisson family for our models. We performed a stepwise logistic regression using the step function to identify the best-fit models. We considered models with the lowest AIC score to explain and discuss the response of ant species richness to environmental parameters. We tested for any misspecification problems in the models such as over-or underdispersion, zero inflation, and quantile deviations using the DHARMa package (Hartig 2020). We found underdispersion in our models with exotic ant species richness and corrected it by using the Conway-Maxwell-Poisson (COMPOIS) distribution (Huang 2017).

\section{Results}

\section{Ant species richness across land-use types}

Old-growth forest, forest fragment, and forest-derived vanilla agroforest had significantly higher endemic ant species richness than the other land-use types $(\mathrm{p}<0.01$, Fig. 2a, Supplementary Material S6). Rice paddy had the lowest endemic ant species richness (Fig. 2a, Supplementary Material S6). Old-growth forest and forest fragment had significantly lower exotic ant species richness than the previously burned land-use types and rice paddy $(\mathrm{p}<0.01$, Fig. 2b, Supplementary Material S7). Rice paddy had significantly lower non-endemic native ant species richness compared to forest fragment $(\mathrm{p}<0.01)$, forest-derived vanilla agroforest 

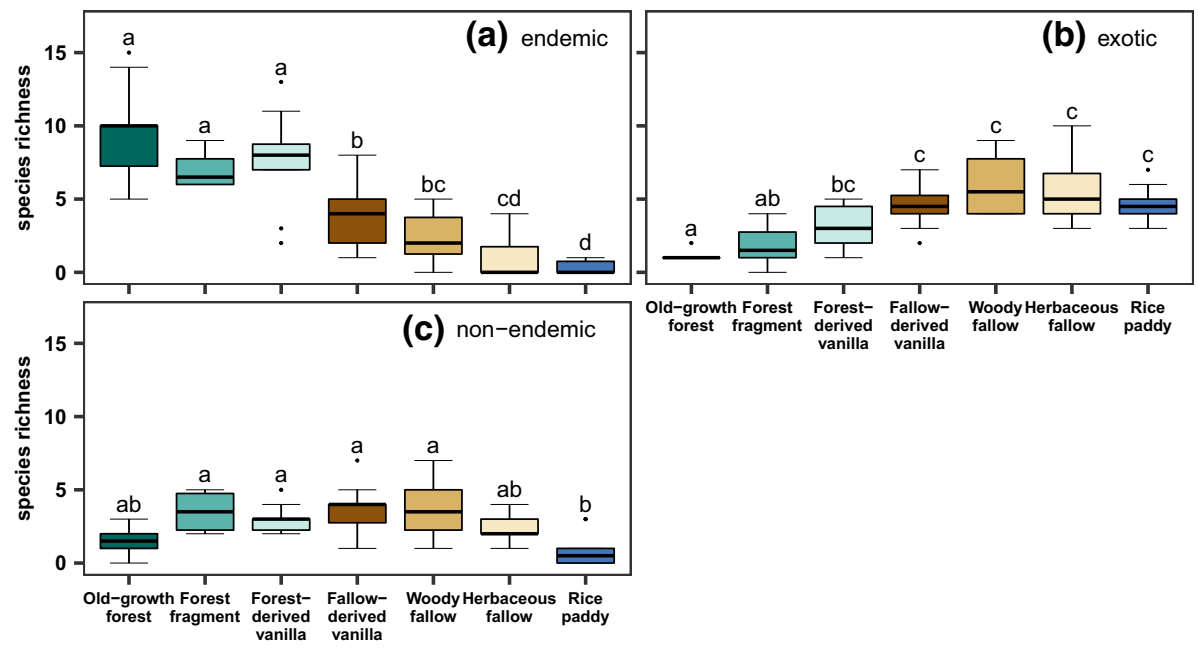
forest fragment derived derived fallow fallow paddy

Fig. 2 Ant species richness across land-use types: a endemic, b exotic ant species c non-endemic native. Non-shared letters between land-use types indicate a significant difference (Tukey's HSD multicomparison with Bonferroni correction, p-value $<0.05$ )

$(\mathrm{p}=0.024)$, fallow-derived vanilla agroforest $(\mathrm{p}<0.01)$, and woody fallow $(\mathrm{p}<0.01)$ (Fig. $2 \mathrm{c}$, Supplementary Material S8).

\section{Species composition of endemic, exotic, and non-endemic native ant across land-use types}

We found a significant gradient in the endemic (PERMANOVA, $\mathrm{df}=6, \mathrm{~F}=2.96, \mathrm{R}^{2}=0.23$, $\mathrm{p}=0.001$ ), exotic (PERMANOVA, $\mathrm{df}=6, \mathrm{~F}=8.88, \mathrm{R}^{2}=0.42, \mathrm{p}=0.001$ ), and non-endemic native (PERMANOVA, $\mathrm{df}=6, \mathrm{~F}=5.93, \mathrm{R}^{2}=0.35, \mathrm{p}=0.001$ ) ant species composition across land-use types (Fig. 3). Old-growth forest significantly differed from all land-use types in both endemic and exotic ant species composition (Fig. 3a, b, Supplementary Material S9 and S10). Forest-derived vanilla agroforest was similar to forest fragment in endemic, exotic, and nonendemic native ant species composition, whereas forest-derived vanilla agroforest differed significantly from fallow-derived vanilla agroforest (Fig. 3a-c, Supplementary Material S9-S11). Endemic and non-endemic native ant species composition was similar among all formerly burned land-use types, whereas differences in exotic species composition among formerly burned land-uses (e.g. rice paddy vs. woody fallow; herbaceous fallow vs. fallow-derived vanilla agroforest) occurred (Fig. 3a-c, Supplementary Material S9-S11). Old-growth forest had the highest number of unique endemic ant species ( 9 species), followed by forest-derived vanilla agroforest (6 species). Forest fragment shared all its endemic species to all land-use types in the agricultural matrix (Fig. 4a). All exotic and non-endemic native ant species were shared between land-use types (Fig. 4b, c).

\section{Environmental factors driving ant species richness in the agricultural matrix}

We found that higher canopy closure (estimate $=0.36837$, standard error $=0.07852$, $\mathrm{z}$-value $=4.692, \mathrm{p}<0.001$ ) and landscape forest cover (estimate $=0.12842$, standard 

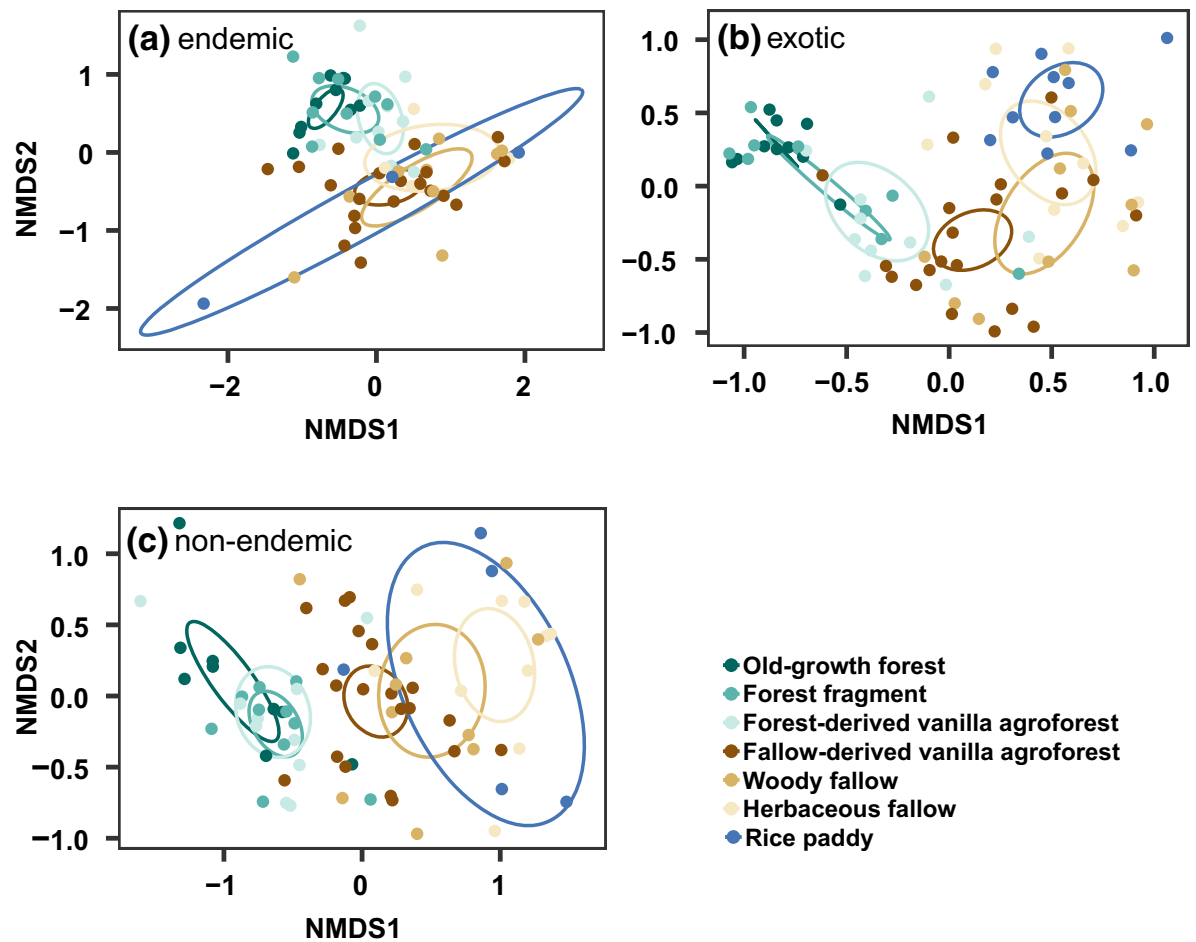

Fig. 3 Ant species composition across land-use types. Non-metric multidimensional scaling plot showing the species composition pattern of a endemic $\left(k=5\right.$, linear fit $R^{2}=0.959$, non-metric fit $R^{2}=0.996$, stress $=0.065)$, b exotic $\left(k=5\right.$, linear fit $R^{2}=0.964$, non-metric fit $R^{2}=0.997$, stress: 0.058$)$ and $\mathbf{c}$ nonendemic native ants $\left(k=5\right.$, linear fit $\mathrm{R}^{2}=0.987$, non-metric fit $\mathrm{R}^{2}=0.999$, stress $\left.=0.038\right)$. Each point represents one plot. We used jittering with width $=0.2$ and height $=0.2$ to avoid overplotting. Ellipses show the $95 \%$ confidence intervals for the estimated center of each land-use type fitted into the spatial ordination. Non-overlapping ellipses indicate significant difference in species composition between land-use types (in line with the pairwise comparison in Supplementary Material S9-S11)

error $=0.06535, \mathrm{z}$-value $=1.965, \mathrm{p}=0.0494)$ were positively related to endemic ant species richness (Fig. 5a, d). In contrast, higher canopy closure (estimate $=-0.18884$, standard error $=0.06160, \mathrm{z}$-value $=-3.066, \mathrm{p}=0.00217$ ) and landscape forest cover (estimate $=-0.21259$, standard error $=0.07685, \quad \mathrm{z}$-value $=-2.766, \mathrm{p}=0.00567$ ) were negatively related to exotic species richness (Fig. 5b, e). We found no significant association between endemic and exotic ant species richness with deadwood volume and understory vegetation cover (Fig. 5g, h, j, k). None of the environmental parameters significantly affected non-endemic native ant species richness (Fig. 5c, f, i, l).

\section{Discussion}

Our study showed that smallholder land use differentially affected endemic and exotic ant communities in north-eastern Madagascar, a global biodiversity hotspot. Endemic and non-endemic native ant species richness was not significantly affected by forest 
(a) endemic

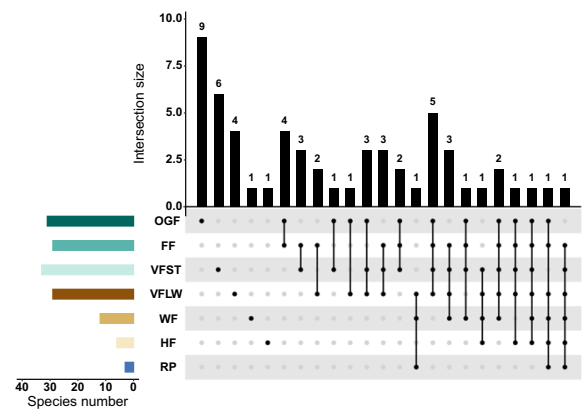

(b) exotic

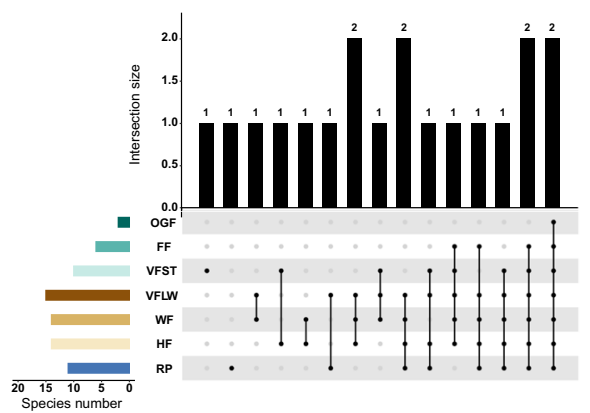

(c) non-endemic native

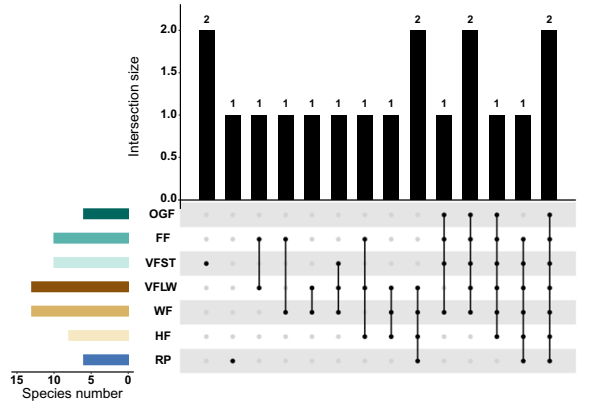

\author{
OGF: Old-growth forest \\ FF: Forest fragment \\ VFST: Forest-derived vanilla agroforest \\ VFLW: Fallow-derived vanilla agroforest \\ WF: Woody fallow \\ HF: Herbaceous fallow \\ RP: Rice paddy
}

Fig. 4 Upset plots showing the number of unique and shared $\mathbf{a}$ endemic, $\mathbf{b}$ exotic, and $\mathbf{c}$ non-endemic native ant species across land-use types. The upper part of each graph shows the number of species found in the land-use type indicated by the dots in the lower part. The simple dots without connecting lines represent the unique species found in the land-use type. As an example, the old-growth forest has 9 unique endemic species. Two or more dots connected by a line indicate a shared species between two or more land-use types, which correspond to the number on the bar of the upper part of the graph. For example, old-growth forest and forest fragment share: 1 st connecting line $=4,2 \mathrm{nd}=2,3 \mathrm{rd}=5,4 \mathrm{th}=1,5 \mathrm{th}=2,6 \mathrm{th}=1,7 \mathrm{th}=1,8 \mathrm{th}=1$, making up in total 17 shared species

conversion to forest-derived vanilla agroforests, but endemic ant richness markedly decreased when forests were transformed via slash-and-burn practices to hill rice cultivation. On the contrary, forest transformation promoted exotic ants, with higher exotic species richness in land-uses in the agricultural matrix compared to old-growth forest sites. In addition, we found that endemic ant species composition was different in the old-growth forest compared to all other land-use types, highlighting the uniqueness of old-growth forests for endemic ant species that are less resilient to disturbance. The exotic ant community in the old-growth forest was only a small subset of the exotic community in the agricultural matrix. In regards to vanilla, endemic, exotic, and nonendemic native ant species composition differed between forest- and fallow-derived vanilla agroforests. Finally, higher canopy closure and landscape forest cover were associated with higher endemic ant species richness but lower exotic ant species richness, suggesting an opportunity for management measures conserving endemic ants as well as mitigating the invasion of exotic ants. 

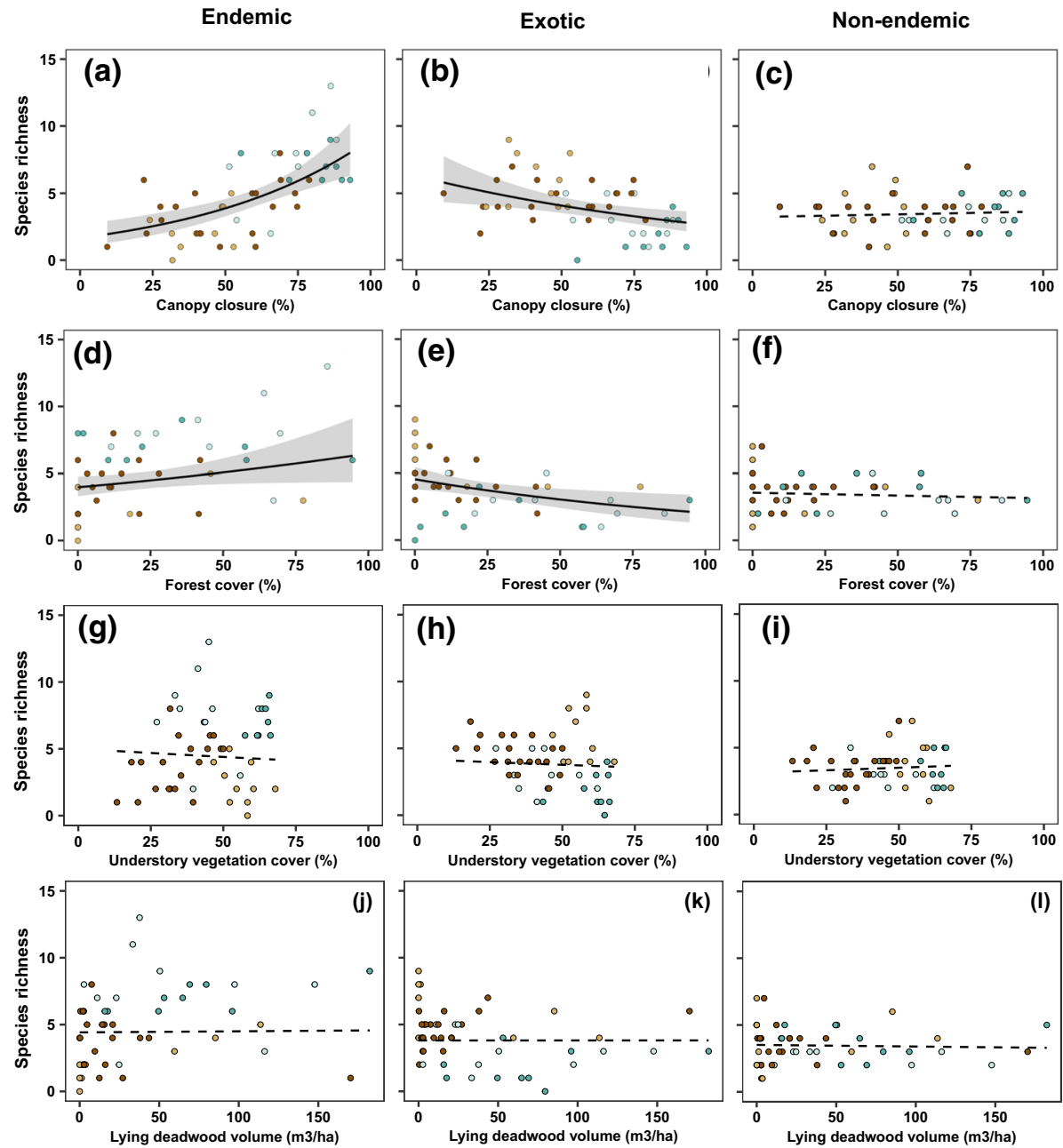

- Forest fragment Forest-derived vanilla

Fig. 5 Endemic and exotic ant species richness in relation to canopy closure, landscape forest cover, understory vegetation cover, and deadwood volume in north-eastern Madagascar (across forest fragment, forest- and fallow-derived vanilla agroforests, and woody fallow plots). Solid regression lines show significant model predictions ( $\mathrm{p}$-value $<0.05$ ), whereas dashed lines show a non-significant relationship. Ribbons indicate $95 \%$ confidence intervals

\section{Ant species richness response to land-use change}

Although the transformation of forests to agroforests usually leads to habitat degradation and species loss (Martin et al. 2020a), our study showed that the endemic ant species richness was not significantly affected by forest conversion to forest-derived vanilla agroforests. This could be explained by the complex structure of forest-derived vanilla agroforests, which still retain a considerable proportion of the original forest structure (Osen et al. 
2021), possibly providing diverse food resources and microhabitats for many endemic ant species. Our finding corroborates research showing that complex agroforests can harbor the same or even higher ant species richness compared to forests (Schroth et al. 2004; Philpott et al. 2008).

In contrast, endemic ant species richness dropped by up to $90 \%$ when forests were transformed via slash-and-burn agriculture practices (from 9.6 mean species richness in the old-growth forest to 0.9 in herbaceous fallow). Even after years of fallow succession from herbaceous to woody fallows, the endemic ant species richness still did not recover to reach the species levels found in the forests. Slash-and-burn constitutes an extreme form of land conversion because it consists of a complete removal of the vegetation through burning (Styger et al. 2007). This potentially leads to a direct loss of microhabitats and resources for many endemic ant species, thus forcing them to find another suitable habitat to survive.

Rice paddy is not part of the slash-and-burn cultivation cycle, but we included this landuse type in our study as it is very common in the study area and refers to permanent and intensive land use. Rice paddy is characterized by mostly inundated areas for rice cultivation and banks covered with herbaceous plants which are frequently walked, thereby limiting the availability of microhabitats such as leaf litter and deadwood, which are important nesting sites for many ant species (Queiroz et al. 2013). This could explain our finding that rice paddy exhibited the lowest endemic and non-endemic native ant species richness compared to the other land-use types.

We provide evidence that exotic ant species are positively affected by human disturbance (Folgarait 1998; Rizali et al. 2010). We found that the old-growth forest had five times lower exotic ant species richness than herbaceous fallow. This could be because exotic ant species generally have a high capacity for adaptation and competition allowing them to co-occur with or dominate native ant species in disturbed habitats (Wetterer 2007). It is important to note that the invasion of exotic ant species could harm native (endemic) ant species (Holway et al. 2002). For example, in Indonesia, the presence of invasive yellow crazy ants, Anoplolepis gracilipes, reduced native ant species in cacao agroforests (Bos et al. 2008). Also, in Australia's monsoonal tropics, Pheidole megacephala, the socalled African big-headed ant, constitutes a big threat to the native ant community because of their aggressive behavior (Hoffmann et al. 1999). However, evidence of the impact of exotic ant species on Madagascar's native ant fauna is scarce. Only Dejean et al. (2010) found that the white-footed ant, Technomyrmex albipes, exhibited aggressive competition on food resources towards the native ant community. This suggests the need for further research on competition between exotic ants and native ant species in Madagascar.

\section{Ant species composition response to land-use change}

We found a clear difference in endemic ant species composition in the old-growth forest compared to all other land-use types, highlighting the uniqueness of the old-growth forest. Old-growth forests, compared to all other land-use types, had nine unique endemic ant species, which according to the AntWeb (2020) database, have never been found in a disturbed habitat. This finding stresses the need to safeguard the old-growth forest to ensure the conservation of endemic ant species that are more sensitive to disturbance. The uniqueness of our old-growth forest sites is also consistent with plant species composition (Osen et al. 2021; Raveloaritiana et al. 2021) and bird species richness (Martin et al. 2021).

We also found a pronounced compositional difference in endemic and non-endemic native ant species between unburned (forest fragment and forest-derived vanilla agroforest) and 
land-use types derived from previous slash-and-burn cultivation (fallows and fallow-derived vanilla agroforest) in the agricultural matrix. This highlights the negative effect of past burning in endemic and non-endemic native ant species composition. Our findings are also in line with another study in the same system, highlighting the change in endemic and native herbaceous plant species composition due to slash-and-burn cultivation (Raveloaritiana et al. 2021).

Besides, our study showed a clear distinction of the exotic ant species composition between unburned and previously burned land-use types and rice paddy. Here, we highlight that oldgrowth forest and forest fragment harbor only a small subset of the exotic ant community occurring in the agricultural matrix. Only two exotic species occurred in the old-growth forest, whereas six species from the exotic ant community in the agricultural matrix occurred in forest fragments. This finding provides evidence that old-growth forest is more resistant to the arrival of certain exotic species than the forest fragment. The susceptibility of the small remnant forest fragment could be due to their proximity to surrounding agricultural lands which serve as a gateway for exotic ant species (Assis et al. 2018).

\section{Management opportunities for endemic ant conservation in the agricultural matrix}

Identifying management practices that maintain endemic biodiversity in agricultural landscapes presents a great opportunity for biodiversity conservation (Kremen and Merenlender 2018). In our study, we found a contrasting effect of canopy closure and landscape forest cover on endemic and exotic ant species richness. This provides clear evidence that keeping higher canopy closure and maintaining a high landscape forest cover can conserve endemic ant species while reducing exotic ant species in the agricultural matrix. For vanilla agroforests specifically, a greater endemic ant species richness could be achieved by promoting trees in fallow-derived and maintaining trees in forest-derived vanilla agroforests. This offers a win-win opportunity for vanilla farmers and the conservation of endemic ant species as a high canopy in vanilla agroforests does not conflict with high vanilla yields (Martin et al. 2020b). Although we did not include tree species richness in our models, it is important to highlight that increasing tree species richness could positively affect ant species richness as shown by other studies (Ribas et al. 2003; Vasconcelos et al. 2019). This suggests that high tree diversity should be maintained in the agricultural matrix to benefit endemic ant species. Here, in particular, the maintenance of already existing forest-derived vanilla agroforests is recommended, as their tree species richness is more similar to forest fragments and old-growth forest than to the other studied land-use types (Osen et al. 2021).

On the other hand, the positive influence of landscape forest cover on endemic species richness suggests that forest fragments could be a source of endemic ant species for the different land-use types in the agricultural matrix (Solar et al. 2016). A previous study also supports that a greater ant species richness within agricultural land can be boosted by large patches of adjacent forests (Lucey et al. 2014). Similarly, in our study, the forest fragment shared all of its endemic ant species with the land-use types in the agricultural matrix. This suggests that remnant forests embedded in the agricultural landscape in north-eastern Madagascar are key to preserve the endemic ant diversity in the agricultural matrix. 


\section{Conclusion}

Our study showed not only the uniqueness of old-growth forest in preserving unique endemic ant species, but also its resistance to the arrival of most exotic ant species. Despite rapidly occurring land-use change in north-eastern Madagascar, the agricultural matrix, still harbors considerable amounts of endemic and non-endemic native ant species. We conclude that preserving remnant forest fragments and promoting vanilla agroforests with a greater canopy closure in the agricultural matrix are important management strategies to complement the role of old-growth forests for endemic ant conservation in north-eastern Madagascar.

Supplementary Information The online version contains supplementary material available at https://doi. org/10.1007/s10531-021-02314-4.

Acknowledgements This research was a part of the "Diversity Turn in Land Use Science" project, funded by the Volkswagen Foundation (Grant Number 11-76251-99-35/13 (ZN3119)). The German Academic Exchange Service (DAAD) supported Anjaharinony Rakotomalala and Marie Rolande Soazafy within the "Partnerships for Supporting Biodiversity in Developing Countries" initiative (Project Nr. 57449386). We thank all plot owners, village chiefs, Madagascar National Parks, Madagascar Biodiversity Center team, for their supports and collaboration which achieved this research. We acknowledge the Ministère de l'Environnement et de Développement Durable (MEDD) in Madagascar allowing us to conduct this research under the permit $\mathrm{N}^{\circ} 100 / 17 / \mathrm{MEEF} / \mathrm{SG} / \mathrm{DGF} / \mathrm{DSAP} / \mathrm{SCB} . \mathrm{Re}, \mathrm{N}^{\circ} 163 / 17 / \mathrm{MEEF} / \mathrm{SG} / \mathrm{DGF} / \mathrm{DSAP} /$

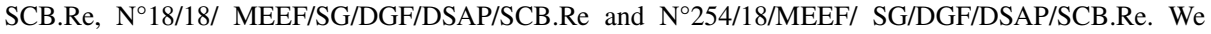
acknowledge Victor Razafindranaivo for his support during the DAAD project application. We thank Evrard Benasoavina for his support during the fieldwork. We also thank Dorah Ramaharobandro for pre-sorting the mixed arthropod samples in the lab. We thank Thorien Rabemanantsoa, Jean Chrysostome Bevao, Patrice Antilahimena, and Adriane März for their support during tree data collection. We are grateful to Thio Rosin Fulgence's contribution to plot selection. We also thank the two reviewers who provided valuable feedback.

Author contributions TT, IG, DAM, KO, and AW conceived the plot design. AR, AW, DAM, KO, and MRS performed the plot selection. AR, AW, TT, and LR designed the ant collection protocol. AR identified the ant specimens, processed and analyzed the data, and led the writing of the manuscript. DS provided the understory vegetation cover data. KO and MRS provided the lying deadwood, tree richness, stem density, and canopy closure data. All authors contributed to the manuscript and gave final approval for publication.

Funding Open Access funding enabled and organized by Projekt DEAL. Volkswagen Foundation, Grant Number 11-76251-99-35/13 (ZN3119). German Academic Exchange Service (DAAD), Project Nr. 57449386.

Data availability Data are available from OSF platform https://osf.io/4nwsz/?view_only=fda54010f0ae4c0 9a381e9fdb7d49acb.

\section{Declarations}

Conflict of interest The authors declare that they have no conflict of interest.

Open Access This article is licensed under a Creative Commons Attribution 4.0 International License, which permits use, sharing, adaptation, distribution and reproduction in any medium or format, as long as you give appropriate credit to the original author(s) and the source, provide a link to the Creative Commons licence, and indicate if changes were made. The images or other third party material in this article are included in the article's Creative Commons licence, unless indicated otherwise in a credit line to the material. If material is not included in the article's Creative Commons licence and your intended use is not permitted by statutory regulation or exceeds the permitted use, you will need to obtain permission directly from the copyright holder. To view a copy of this licence, visit http://creativecommons.org/licenses/by/4.0/. 


\section{References}

AntWeb (2020) Version 8.48.2. California Academy of Science. https://www.antweb.org. Accessed 27 Nov 2020.

Arbizu PM (2017) pairwiseAdonis: pairwise multilevel comparison using adonis. R package version 0.0.1.

Assis DS, Dos Santos IA, Ramos FN et al (2018) Agricultural matrices affect ground ant assemblage composition inside forest fragments. PLoS ONE 13:e0197697. https://doi.org/10.1371/journal.pone.01976 97

Baena S, Beentje H, Cameron A, et al (2007) Atlas of the vegetation of Madagascar. Royal Botanic Gardens, Kew.

Beckschäfer P (2015) Hemispherical_2.0 -Batch processing hemispherical and canopy photographs with Image J -User Manual. https://doi.org/10.13140/RG.2.1.3059.4088

Belshaw R, Bolton B (1993) The effect of forest disturbance on the leaf litter ant fauna in Ghana. Biodivers Conserv 2:56-666

Bolton B, Fisher BL (2014) The Madagascan endemic myrmicine ants related to Eutetramorium (Hymenoptera: Formicidae): taxonomy of the genera Eutetramorium Emery, Malagidris nom. n., Myrmisaraka gen. n., Royidris gen. n., and Vitsika gen. n. Zootaxa 3791:1-99. https://doi.org/10.11646/zootaxa. 3791.1 .1

Bos MM, Tylianakis JM, Steffan-Dewenter I, Tscharntke T (2008) The invasive Yellow Crazy Ant and the decline of forest ant diversity in Indonesian cacao agroforests. Biol Invasions 10:1399-1409. https:// doi.org/10.1007/s 10530-008-9215-4

Brooks ME, Kristensen K, Benthem KJ,van, et al (2017) glmmTMB balances speed and flexibility among packages for zero-inflated generalized linear mixed modeling. R J 9:378. https://doi.org/10.32614/ RJ-2017-066

Cerdá X, Dejean A (2011) Predation by ants on arthropods and other animals. In: Predation in the Hymenoptera: an evolutionary perspective. pp 38-78.

Clark M (2012) Deforestation in Madagascar: consequences of population growth and unsustainable agricultural processes. Global Majority E-Journal 3:61-71

de Solar RRC, Barlow J, Andersen AN, et al (2016) Biodiversity consequences of land-use change and forest disturbance in the Amazon: a multi-scale assessment using ant communities. Biol Conserv 197:98107. https://doi.org/10.1016/j.biocon.2016.03.005

Dean WRJ, Milton SJ (2018) Ants (Formicidae) as food for birds in southern Africa: opportunism or survival? Ostrich 89:1-4. https://doi.org/10.2989/00306525.2017.1382017

Dejean A, Fisher BL, Corbara B et al (2010) Spatial distribution of dominant arboreal ants in a Malagasy coastal rainforest: gaps and presence of an invasive species. PLoS ONE 5:e9319. https://doi.org/10. 1371/journal.pone.0009319

Delabie JHC, Jahyny B, do Nascimento IC, et al (2007) Contribution of cocoa plantations to the conservation of native ants (Insecta: Hymenoptera: Formicidae) with a special emphasis on the Atlantic Forest fauna of southern Bahia, Brazil. Biodivers Conserv 16:2359-2384. https://doi.org/10.1007/ s10531-007-9190-6

Dormann CF, Elith J, Bacher S et al (2013) Collinearity: a review of methods to deal with it and a simulation study evaluating their performance. Ecography 36:27-46. https://doi.org/10.1111/j.1600-0587. 2012.07348.x

Dunn RR (2004) Managing the tropical landscape: a comparison of the effects of logging and forest conversion to agriculture on ants, birds, and Lepidoptera. For Ecol Manage 191:215-224. https://doi.org/10. 1016/j.foreco.2003.12.008

FAO (2020) Food and Agriculture Organisation of the United Nations. http://www.fao.org/faostat/en

Fisher BL, Christian P (2019) Fourmis de Madagascar: un guide pour les 62 genres/ants of Madagascar: a guide to the 62 genera. Association Vahatra, Madagascar.

Fisher BL, Smith MA (2008) A revision of Malagasy species of Anochetus Mayr and Odontomachus Latreille (Hymenoptera: Formicidae). PLoS ONE 3:e1787. https://doi.org/10.1371/journal.pone.00017 87

Fisher BL, Bolton B, Huppi J (2016) Ants of Africa and Madagascar, 1st edn. University of California Press

Folgarait PJ (1998) Ant biodiversity and its relationship to ecosystem functioning: a review. Biodivers Conserv 7:1221-1244. https://doi.org/10.1023/A:1008891901953

Gardner CJ, Nicoll ME, Birkinshaw C et al (2018) The rapid expansion of Madagascar's protected area system. Biol Conserv 220:29-36. https://doi.org/10.1016/j.biocon.2018.02.011

Gehlenborg N (2019) UpSetR: a more scalable alternative to Venn and Euler diagrams for visualizing intersecting sets. R package version 1.4.0. https://CRAN.R-project.org/package $=\mathrm{UpSetR}$ 
Gibson L, Lee TM, Koh LP et al (2011) Primary forests are irreplaceable for sustaining tropical biodiversity. Nature 478:378-381. https://doi.org/10.1038/nature10425

Goral F, Schellenberg J (2021) goeveg: functions for community data and ordinations. R package version 0.5.1. https://CRAN.R-project.org/package=goeveg

Grass I, Kubitza C, Krishna VV et al (2020) Trade-offs between multifunctionality and profit in tropical smallholder landscapes. Nat Commun 11:1186. https://doi.org/10.1038/s41467-020-15013-5

Hartig F (2020) DHARMa: residual diagnostics for hierarchical (multi-level/mixed) regression models. R package version 0.3.3.0. https://CRAN.R-project.org/package=DHARMa

Hending D, Andrianiaina A, Rakotomalala Z, Cotton S (2018) The use of vanilla plantations by lemurs: encouraging findings for both lemur conservation and sustainable agroforestry in the Sava Region, Northeast Madagascar. Int J Primatol 39:141-153. https://doi.org/10.1007/s10764-018-0022-1

Hending D, Andrianiaina A, Maxfield P et al (2020) Floral species richness, structural diversity and conservation value of vanilla agroecosystems in Madagascar. Afr J Ecol 58:100-111. https://doi. org/10.1111/aje.12682

Hoffmann BD, Andersen AN, Hill GJE (1999) Impact of an introduced ant on native rain forest invertebrates: Pheidole megacephala in monsoonal Australia. Oecologia 120:595-604. https://doi.org/10. 1007/PL00008824

Holway DA, Lach L, Suarez AV et al (2002) The causes and consequences of ant invasions. Annu Rev Ecol Syst 33:181-233. https://doi.org/10.1146/annurev.ecolsys.33.010802.150444

Huang A (2017) Mean-parametrized Conway-Maxwell-Poisson regression models for dispersed counts. Stat Model 17:1-22. https://doi.org/10.1177/1471082X17697749

Irwin MT, Wright PC, Birkinshaw C et al (2010) Patterns of species change in anthropogenically disturbed forests of Madagascar. Biol Conserv 143:2351-2362. https://doi.org/10.1016/j.biocon.2010. 01.023

Karger DN, Conrad O, Böhner J et al (2017) Climatologies at high resolution for the earth's land surface areas. Scientific Data 4:170122. https://doi.org/10.1038/sdata.2017.122

Kremen C, Merenlender AM (2018) Landscapes that work for biodiversity and people. Science 362:eaau6020. https://doi.org/10.1126/science.aau6020

Lach L, Parr CL, Abbott KL (eds) (2010) Ant ecology. Oxford University Press, Oxford

Llopis JC, Harimalala PC, Bär R et al (2019) Effects of protected area establishment and cash crop price dynamics on land use transitions 1990-2017 in north-eastern Madagascar. J Land Use Sci 14:5280. https://doi.org/10.1080/1747423X.2019.1625979

Lucey JM, Tawatao N, Senior MJM et al (2014) Tropical forest fragments contribute to species richness in adjacent oil palm plantations. Biol Conserv 169:268-276. https://doi.org/10.1016/j.biocon.2013. 11.014

Luke SH, Fayle TM, Eggleton P et al (2014) Functional structure of ant and termite assemblages in old growth forest, logged forest and oil palm plantation in Malaysian Borneo. Biodivers Conserv 23:2817-2832. https://doi.org/10.1007/s10531-014-0750-2

Martin DA, Osen K, Grass I et al (2020a) Land-use history determines ecosystem services and conservation value in tropical agroforestry. Conserv Lett 13(5):e12740. https://doi.org/10.1111/conl.12740

Martin DA, Wurz A, Osen K, et al (2020b) Shade-tree rehabilitation in vanilla agroforests is yield neutral and may translate into landscape-scale canopy cover gains. Ecosystems: 1-15. https://doi.org/ 10.1007/s10021-020-00586-5

Martin DA, Andriafanomezantsoa R, Dröge S et al (2021) Bird diversity and endemism along a landuse gradient in Madagascar: the conservation value of vanilla agroforests. Biotropica 53:179-190. https://doi.org/10.1111/btp.12859

Myers N, Mittermeier RA, Mittermeier CG et al (2000) Biodiversity hotspots for conservation priorities. Nature 403:853-858. https://doi.org/10.1038/35002501

Oksanen JF, Blanchet G, Friendly M, et al (2018) vegan: community ecology package. R package version 2.5-2. https://CRAN.R-project.org/package=vegan

Osen K, Soazafy MR, Martin DA et al (2021) Land-use history determines stand structure and tree diversity in vanilla agroforests of northeastern Madagascar. Appl Veg Sci 24(1):e12563. https://doi. org/10.1111/avsc. 12563

Ottonetti L, Tucci L, Frizzi F et al (2010) Changes in ground-foraging ant assemblages along a disturbance gradient in a tropical agricultural landscape. Ethol Ecol Evol 22:73-86. https://doi.org/10. $1080 / 03949370903516024$

Passera L, Aron S (2005) Les fourmis: comportement, organisation sociale et évolution. Presses Scientifiques du CNRC, Canada 
Philpott SM, Arendt WJ, Armbrecht I et al (2008) Biodiversity loss in latin american coffee landscapes: review of the evidence on ants, birds, and trees. Conserv Biol 22:1093-1105. https://doi.org/10. 1111/j.1523-1739.2008.01029.x

Queiroz ACM de, Ribas CR, França FM (2013) Microhabitat characteristics that regulate ant richness patterns: the importance of leaf litter for epigaeic ants. Sociobiology 60:367-373. https://doi.org/ 10.13102/sociobiology.v60i4.367-373

R Core Team (2020) R: a language and environment for statistical computing. R Foundation for Statistical Computing, Vienna, Austria. https://www.R-project.org/

Rakotonirina JC, Fisher BL (2014) Revision of the Malagasy ponerine ants of the genus Leptogenys Roger (Hymenoptera: Formicidae). Zootaxa 3836:1. https://doi.org/10.11646/zootaxa.3836.1.1

Rasband WS (2014) ImageJ. Bethesda, MA: U. S. National Institutes of Health. Available from: https:// imagej.nih.gov/ij/

Raveloaritiana E, Wurz A, Grass I, et al (2021) Land-use intensification increases richness of native and exotic herbaceous plants, but not endemics, in Malagasy vanilla landscapes. Divers Distrib https:// doi.org/10.1111/ddi.13226

Retana J, Xavier Picó F, Rodrigo A (2004) Dual role of harvesting ants as seed predators and dispersers of a non-myrmechorous Mediterranean perennial herb. Oikos 105:377-385. https://doi.org/10.1111/j.00301299.2004.12854.x

Ribas CR, Schoereder JH, Pic M, Soares SM (2003) Tree heterogeneity, resource availability, and larger scale processes regulating arboreal ant species richness. Austral Ecol 28:305-314. https://doi.org/10. 1046/j.1442-9993.2003.01290.x

Rizali A, Lohman DJ, Buchori D et al (2010) Ant communities on small tropical islands: effects of island size and isolation are obscured by habitat disturbance and 'tramp' ant species. J Biogeogr 37:229-236. https://doi.org/10.1111/j.1365-2699.2009.02194.x

Rondeux J, Bertini R, Bastrup-Birk A et al (2012) Assessing deadwood using harmonized national forest inventory data. Forest Sci 58:269-283. https://doi.org/10.5849/forsci.10-057

Salata S, Fisher BL (2020) Pheidole Westwood, 1839 (Hymenoptera, Formicidae) of Madagascar-an introduction and a taxonomic revision of eleven species groups. ZooKeys 905:1-235. https://doi.org/ 10.3897/zookeys.905.39592

Schroth G, Harvey CA, Vincent G (2004) Complex Agroforests: their structure, diversity, and potential role in landscape conservation. In: Agroforestry and biodiversity conservation in tropical landscapes. Island Press, Washington, p 34.

Schwab D, Wurz A, Grass I et al (2021) Decreasing predation rates and shifting predator compositions along a land-use gradient in Madagascar's vanilla landscapes. J Appl Ecol 58:360-371. https://doi.org/ $10.1111 / 1365-2664.13766$

Styger E, Rakotondramasy HM, Pfeffer MJ et al (2007) Influence of slash-and-burn farming practices on fallow succession and land degradation in the rainforest region of Madagascar. Agr Ecosyst Environ 119:257-269. https://doi.org/10.1016/j.agee.2006.07.012

UPDR (2003) Monographie de la région du Sava. Ministère de l'agriculture, de l'élevage et de la pèche. Madagascar.

Van Der Maarel E (1966) Vegetationsstruktur und Minimum-Areal in Einem Dünen-Trockenrasen. In: Tüxen R (eds) Gesellschaftsmorphologie. Bericht Über das Internationale Symposion der Internationalen Vereinigung für Vegetationskunde in Rinteln. Springer, Dordrecht, pp 218-239.

Vasconcelos HL, Maravalhas JB, Neves KC et al (2019) Congruent spatial patterns of ant and tree diversity in Neotropical savannas. Biodivers Conserv 28:1075-1089. https://doi.org/10.1007/ s10531-019-01708-9

Vieilledent G, Grinand C, Rakotomalala FA et al (2018) Combining global tree cover loss data with historical national forest cover maps to look at six decades of deforestation and forest fragmentation in Madagascar. Biol Conserv 222:189-197. https://doi.org/10.1016/j.biocon.2018.04.008

Wetterer JK (2007) Biology and impacts of pacific island invasive species. 3. The African big-headed ant, Pheidole megacephala (Hymenoptera: Formicidae). Pac Sci 61:437-456

Zaehringer J, Eckert S, Messerli P (2015) Revealing regional deforestation dynamics in north-eastern Madagascar-insights from multi-temporal land cover change analysis. Land 4:454-474. https://doi.org/10. 3390/land4020454

Publisher's Note Springer Nature remains neutral with regard to jurisdictional claims in published maps and institutional affiliations. 


\section{Authors and Affiliations}

Anjaharinony A. N. A. Rakotomalala ${ }^{1,2}$ (D) Annemarie Wurz ${ }^{2}$. Ingo Grass ${ }^{3}$ (D) . Dominic A. Martin ${ }^{4,5}$ (D) Kristina Osen ${ }^{6}$ (D) . Dominik Schwab ${ }^{2}$ (D) Marie Rolande Soazafy ${ }^{6,7,8}$ (D) Teja Tscharntke ${ }^{2,9}$ (D) Lala H. Raveloson Ravaomanarivo ${ }^{1}$

1 Entomology Department, Faculty of Science, University of Antananarivo, PO Box 906, 101 Antananarivo, Madagascar

2 Agroecology, Department of Crop Sciences, University of Göttingen, Grisebachstrasse 6, 37077 Göttingen, Germany

3 Ecology of Tropical Agricultural Systems, Institute of Agricultural Sciences in the Tropics (Hans-Ruthenberg-Institute), University of Hohenheim, Garbenstrasse 13, 70599 Stuttgart, Germany

4 Biodiversity, Macroecology, and Biogeography, University of Göttingen, Büsgenweg 1, 37077 Göttingen, Germany

5 Wyss Academy for Nature, University of Bern, Kochergasse 4, 3011 Bern, Switzerland

6 Tropical Silviculture and Forest Ecology, University of Göttingen, Büsgenweg 1, 37077 Göttingen, Germany

7 Natural and Environmental Sciences, Regional University Centre of the SAVA Region (CURSA), Antalaha, Madagascar

8 Doctoral School of Natural Ecosystems (EDEN), University of Mahajanga, Mahajanga, Madagascar

9 Centre for Biodiversity and Sustainable Land Use (CBL), University of Göttingen, Büsgenweg 1, 37077 Göttingen, Germany 